Article

\title{
Economic Value of Improving Natural Gas Supply Reliability for Residential Consumers in South Korea
}

\author{
Hyo-Jin Kim, Sung-Min Kim and Seung-Hoon Yoo * (1) \\ Department of Energy Policy, Graduate School of Energy \& Environment, Seoul National University of Science \\ \& Technology, 232 Gongreung-Ro, Nowon-Gu, Seoul 01811, Korea; hjinkim@seoultech.ac.kr (H.-J.K.); \\ sungminkim@seoultech.ac.kr (S.-M.K.) \\ * Correspondence: shyoo@seoultech.ac.kr
}

Received: 10 November 2018; Accepted: 12 January 2019; Published: 19 January 2019

\begin{abstract}
An interruption to residential natural gas (NG) may cause considerable economic damage of the entire country. Thus, the South Korean government requires information about the economic value of improving residential NG supply reliability for planning NG supply. This article aims to measure the value using a specific case of South Korean residential consumers. The choice experiment (CE) approach was adopted for this purpose. The selected four attributes are the duration of interruption, the season of interruption, the time of day, and the day of the week. The value trade-off works among the four attributes and price attribute were sought and completed in a nationwide CE survey of 1000 households. The respondents revealed statistically significant willingness to pay for a decrease in the duration of interruption, avoiding interruption during winter rather than non-winter, and preventing interruption during off-daytime (18:00 to 09:00) rather than daytime (09:00 to 18:00). For example, they accepted a $0.10 \%$ increase in the residential NG bill for a one-minute reduction in interruption during NG supply interruption, a 5.16\% increase in residential NG bill for avoiding interruption during winter rather than non-winter, and a $2.94 \%$ increase in residential NG bill for preventing interruption during off-daytime rather than daytime. However, they placed no importance on the day of the week. These results can be useful for policy-making and decision-making to improve residential NG supply reliability. It is necessary to conduct a study at regular intervals on the value of NG supply reliability because regarding NG supply reliability, it is difficult to maintain a specific value.
\end{abstract}

Keywords: supply reliability; natural gas; choice experiment; willingness to pay

\section{Introduction}

The annual average distribution rate of residential natural gas (NG) in South Korea had quadrupled from $21.7 \%$ in 1992 to $83.1 \%$ at the end of 2017, in 25 years. Although the percentage of NG used in industrial production is decreasing, the proportion of residential NG is increasing. Since 1987, use of residential NG was limited to cooking but, since the 1990s, residential NG was mainly supplied for heating.

Thus, NG is an essential source of energy to households in South Korea, and a stable NG supply in the residential sector contributes to social welfare. Residential NG is used for cooking and heating (hot water) at home. The percentage of households using NG exceeded $80.7 \%$ of total households in South Korea in 2016. Furthermore, the proportion of households using NG in Seoul, the capital of South Korea, exceeded $98 \%$ of its total households in 2016 [1]. If NG is not supplied properly to households, massive damage will take place.

In particular, the daily average temperature reaches $-10{ }^{\circ} \mathrm{C}$ to $10^{\circ} \mathrm{C}$ in December and February in South Korea, so the demand for heating increases rapidly in the cold winter. Since most households 
are heated using individual heating boilers that use NG as a fuel, more damage can occur when NG supply interruption takes place in winter than in other seasons. Therefore, there is a consensus among the people that an NG supply interruption should not happen.

Moreover, the stable supply of NG to the residential sector will be the most important issue for the public, given that the abnormal cold wave will continue in the future. Thus, the old gas pipe needs to be replaced, and the gas pipeline needs to be maintained to prevent NG supply interruption. This requires a large investment. To justify the investment, the benefits of the investment must outweigh its costs related to the investment.

Determining the optimal level of NG supply reliability requires a function of the cost needed to improve NG supply reliability and a function of damage costs reduced by improving NG supply reliability. The optimal level of NG supply reliability is determined at a level that minimizes the sum of the two cost functions. In particular, the function of damage costs reduced due to improved NG supply reliability is the same as the function of economic value resulting from improved NG supply reliability. Therefore, it is necessary to develop a function that represents the economic value of improving the reliability of NG supply.

The costs of increasing NG supply reliability can be measured without particular difficulties. However, estimating the benefits or economic value arising from the investment for improving NG supply reliability is a complicated task. This is because the outcome of the investment is improved supply reliability of NG and NG supply reliability is not a commodity traded in the market. It is necessary to apply techniques to create a hypothetical market for trading NG supply reliability so that the reliability of NG supply can be assessed by the consumers. Moreover, NG supply reliability has several attributes, each of which should be valued. In other words, NG supply reliability is a multi-attribute good [2].

Therefore, the application of specially designed economic techniques is required to value a multi-attribute good. A typical way to do this is a choice experiment (CE). CE is the most prevalent methodology for a multi-attribute good and is almost always applied in some previous studies dealing with the valuation of energy supply reliability [3-6]. In this study, the CE is applied to economic value of improving NG supply reliability for residential consumers in South Korea. The four attributes of NG supply reliability considered in this study are the duration of interruption, the season of interruption, the time of day, and the day of the week.

As will be explained in more detail below, this study randomly selected 1000 households from all over the country under the supervision of a professional survey company to apply the CE method. The subsequent composition of this paper is as follows. Section 2 describes, in detail, the methodology and application procedures used in this study. Section 3 explains the economic and statistical models for analyzing data collected through the CE survey. Section 4 presents some implications after reporting the results. The last section provides a conclusion.

\section{Methodology}

\subsection{CE Approach}

Two techniques that have been widely employed for nonmarket good valuation in the literature are the $\mathrm{CE}$ and contingent valuation (CV) [7-10]. The CE method asks the respondents to evaluate value trade-offs among some attributes and indirectly derives their willingness to pay (WTP). Usually, the CV method is applied to a single-attribute good while the CE method is applied to a multi-attribute good. Therefore, the CE method is more suitable for valuing a multi-attribute good than the CV method. The CE approach is theoretically grounded in the random utility maximization model. The model implies that if an individual chooses one alternative among several alternatives, the utility arising from the alternative is always more than the utility arising from the other alternatives. Therefore, the application of the approach requires a survey of consumers. CE is a useful method for estimating the relative values for different attributes of an environmental and nonmarket good or new product. 
The CE approach is a standardized and widely used survey method for estimating WTP [11]. The distinguished National Oceanic and Atmospheric Administration's (NOAA) Panel concluded that the $\mathrm{CE}$ approach can produce estimates that are reliable enough to be the starting point for administrative and judicial determinations and presented several recommendations [11]. In addition, the validity and accuracy of a CE study can be enhanced if people are familiar with the good to be valued; professional interviewers are used; and other conventions suggested by the NOAA Panel are followed. Our study meets the conditions, which will be discussed below in detail.

Our research can be compared with the previous research on three points. First, the studies that investigated NG supply reliability. Most of the related research has improved power supply reliability [12-16]. In this regard, this study can contribute to the literature on the economic value of improving NG supply reliability for residential consumers in South Korea. In particular, there is no previous research that investigated the economic value of improving NG supply reliability in other countries as well as South Korea.

Second, our application of the CE technique coincides with the practice adopted in former studies dealing with this kind of research topic. Moreover, the CE technique is based on microeconomics and, thus, is theoretically sound [17]. Since the findings obtained in this article can be used in policy-making and analysis, it is crucial to use reasonable and sound methodology. The CE technique is not only practically useful, but also theoretically robust.

Third, we tried to follow several guidelines recommended for applying the CE approach in the literature. They include a minimum sample size of 1000, the announcement of the possible presence of substitutes for the goods to be investigated in the CE survey, and so on. More details will be presented in the next subsections.

In general, respondents are required to choose the most preferred alternative out of several alternatives, which include a current status alternative, presented to them in the CE survey. Each alternative comprises several attributes of concern, including the price attribute. $C E$ is a useful method to estimate the relative importance of several attributes for a good or service. Marginal WTP (MWTP) for increasing or decreasing the level of each attribute can be obtained through analyzing the data on respondents' choices and then interpreting or utilizing the results.

\subsection{Attributes}

In designing a $\mathrm{CE}$, the first important thing to do is to determine the appropriate attributes and define their levels. An extensive literature review and consultation with experts enabled us to identify a preliminary list of attributes of NG supply reliability. Most previous studies reveal that the duration of energy supply interruption, the season of energy supply interruption, the energy supply interruption time of day, and the energy supply interruption day of the week have important implications for the value of improved energy supply reliability [16-20]. The final set of attributes was chosen by discussing with experts, such as policy-makers, stakeholders, and environmental activists.

The attributes used in this study were chosen based on four criteria. First, we referred to the attributes used in the preceding studies that dealt with the assessment of the economic value of improvement in supply reliability in the network sectors, such as NG or electricity. Second, we reflected the policy variables in which South Korea NG authority have interests concerning improvement of the residential NG supply reliability. Third, the attributes should be meaningful, easily understandable, and persuasive to individual households in relation to the residential NG supply reliability. Fourth, attributes should be independent of each other. In this context, independence means independence from the perspective of respondents' valuation function, not from the point of view of the production function that generates each attribute.

As reported in Table 1, the finally determined attributes are the duration of interruption, the season of interruption, the time of day, the day of the week, and the price. A focus group interview with 30 people was implemented to check for whether the survey questionnaire is fully meaningful, understandable, and persuasive to the respondents. Their responses were affirmative. The descriptions 
and levels of them are also explained in Table 1. Furthermore, all other attributes of residential NG supply reliability are assumed to be the same in the course of the value judgments required in the CE survey.

Table 1. Descriptions and levels of four chosen attributes and price attribute used in this study

\begin{tabular}{|c|c|c|}
\hline Attributes & Descriptions & Levels \\
\hline Duration of interruption & $\begin{array}{l}\text { Duration of residential natural gas } \\
\text { (NG) supply interruption }\end{array}$ & $\begin{array}{l}\text { Level 1: } 120 \mathrm{~min} \\
\text { Level 2: } 60 \mathrm{~min} \\
\text { Level 3: } 20 \mathrm{~min}\end{array}$ \\
\hline Season of interruption & $\begin{array}{l}\text { Season when residential NG supply } \\
\text { interruption takes place }\end{array}$ & $\begin{array}{l}\text { Level 1: Winter \# } \\
\text { Level 2: Non-winter }\end{array}$ \\
\hline Time of day & $\begin{array}{l}\text { Time when residential NG supply } \\
\text { interruption occurs }\end{array}$ & $\begin{array}{l}\text { Level 1: Day time \# (09:00 to } 18: 00) \\
\text { Level 2: Off-daytime (18:00 to 09:00) }\end{array}$ \\
\hline Day of week & $\begin{array}{l}\text { Day when residential NG supply } \\
\text { interruption happens }\end{array}$ & $\begin{array}{l}\text { Level 1: Weekday } \\
\text { Level 2: Weekend }\end{array}$ \\
\hline Price & $\begin{array}{l}\text { Percentage of an additional payment } \\
\text { for residential NG use (\%) }\end{array}$ & $\begin{array}{l}\text { Level 1: } 0^{\#} \\
\text { Level 2: 1\% } \\
\text { Level 3: 5\% } \\
\text { Level 4: } 10 \% \\
\text { Level 5: } 20 \%\end{array}$ \\
\hline
\end{tabular}

Note: \# indicates the baseline status of each attribute.

Usually, the NG supply reliability decreases when residential NG supply interruption takes place in winter, daytime, and weekdays. Moreover, the longer the duration of the residential NG supply interruption is, the lower the NG supply reliability. The baseline status of duration of interruption, season of interruption, time of day, and day of week means the level with the most negative situation. The level of the attribute for price is explained as the percentage of an additional payment for residential NG use. Although there is no actual payment, we explained to the respondents that the NG supply reliability for residential consumers could be improved by increasing the residential NG bill. The baseline status of this attribute means that there is no additional payment in the most negative situation.

\subsection{Choice Sets}

Since a number of alternatives can be developed from Table 1, several alternatives from possible combinations of attributes should be derived. To this end, the orthogonal main effects design was employed, and 16 alternatives were obtained. From these, eight choice sets were generated. Each choice set was made up of two alternatives and the baseline status alternative. Four choice sets were randomly selected among eight choice sets and allocated to the first group, and then the remaining four choice sets were assigned to the second group. Thus, each group included four choice sets. One of the two groups was randomly presented to each interviewee. In other words, each interviewee was presented with four choice sets and reported four responses to the provided questions that indicated which alternatives were the most preferred among the three alternatives in each choice set.

\subsection{Survey Instrument and Method}

There are three parts in the survey instrument. Several questions about the NG supply reliability make up the first part to check respondents' perceptions before the CE survey on NG supply reliability begins in earnest. To facilitate the respondents' understanding, a description of the features and effects of NG supply reliability is provided, along with color photographs, in this section. Such work not only relieves respondents of the burden of a fully fledged survey, but also provides significant statistical data in itself. Explanations about the attributes and questions concerning the value trade-off work, which are conventionally required in a CE survey, are presented in the second part. The third part contains questions about the respondents' socioeconomic information. 
A random sampling method was commissioned by an expert who was affiliated with a professional survey firm; the sampling reflected the population characteristics observed from a census by Statistics Korea, the Korean National Statistical Office. More specifically, stratified random sampling was conducted. The survey firm performed a random sampling and field CE survey during May 2017. According to Statistics Korea, there were 19,523,587 households in Korea in 2017. In order to draw a random sample of this population, stratified random sampling was conducted by the polling firm. Random sampling was conducted within sixteen strata: Seoul, Pusan, Daegu, Incheon Gwangju, Daejeon, Ulsan, Sejong, Gyunggi, Gangwon, Chungbuk, Chungnam, Jeonbuk, Jeonnam, Gyungbuk, and Gyungnam. The sizes of stratum for Seoul, Pusan, Daegu, Incheon, Gwangju, Daejeon, Ulsan, Sejong, Gyunggi, Gangwon, Chungbuk, Chungnam, Jeonbuk, Jeonnam, Gyungbuk, and Gyungnam were $201,72,50,57,29,30,23,4,239,31,31,41,37,36,54$, and 65 , respectively. The sampling within each stratum reflected each stratum's population characteristics such as age, income, and gender.

\section{Model}

\subsection{Utility Function}

We assume that the utility function has a linear functional form. Let the levels of Duration of interruption, Season of interruption, Time of day, Day of week, and Price be $X_{t}$, where $t=1,2,3,4, p$. In addition, an alternative-specific constant (ASC) is introduced to capture the effect of any other factors not contained in the model. ASC represents a dummy for the respondent choosing the baseline status option among three alternatives. ASC is 1 if the respondent chooses the third alternative (baseline status), 0 otherwise. Let $V_{j l}$ be the utility for interviewee $j$ who chooses alternative $l$. The utility function is formulated as

$$
\begin{aligned}
& V_{j l}=W_{j l}\left(X_{j l}, T_{j}\right)+\varepsilon_{j l} \\
& \quad=A S C_{j}+\beta_{1} X_{1, j l}+\beta_{2} X_{2, j l}+\beta_{3} X_{3, j l}+\beta_{4} X_{4, j l}+\beta_{p} X_{p, j l}+\varepsilon_{j l}
\end{aligned}
$$

where $W_{j l}$ and $\varepsilon_{j l}$ are the deterministic and stochastic parts of the utility function, respectively; $X_{j l}$ is a vector containing the levels of the attributes for alternative $l$ given to respondent $j ; T_{j}$ is respondent $j$ 's characteristics, such as ASC; and the $\beta^{\prime}$ s are the coefficients that correspond to each attribute.

For simplicity, $j l$ is omitted here. $X_{2, j l}$ is coded as 0 and 1 in case of winter and non-winter, respectively. $X_{3, j l}$ is coded as 0 and 1 in case of day time and off-daytime, respectively. $X_{4, j l}$ is coded as 0 and 1 in case of weekday and weekend, respectively.

We can apply Roy's identity to Equation (1) and derive the MWTP estimate, $M W T P_{X_{t}}$, as

$$
M W T P_{X_{t}}=-\left(\partial W / \partial X_{t}\right) /\left(\partial W / \partial X_{p}\right)=-\beta_{t} / \beta_{p} \text { for } t=1,2,3,4
$$

The MWTPs of each attribute represent the marginal rate of substitution between the price and each attribute.

\subsection{How to Obtain the Utility Function}

Estimating the utility function implies estimating $\beta^{\prime}$ s. Usually, the multinomial logit (MNL) model given by McFadden [21] has been most widely applied to obtain $\beta$ in the literature. However, the MNL model inevitably assumes independence from irrelevant alternatives. Although the assumption seems to be somewhat restrictive, it has the advantage of enabling us to specify the log-likelihood function as a closed form. Thus, if the assumption is met, we can easily tackle the CE data. Let $J$ be the number of interviewees and $I_{j l}$ be a dummy variable that is defined as 1 if interviewee $j$ selects alternative $l$; otherwise, $I_{j l}$ is 0 . The log-likelihood function for our MNL model is 


$$
\ln L=\sum_{j=1}^{J} \ln \left[\frac{\prod_{k=1}^{3}\left(\exp \left(W_{j k}\right)\right)^{I_{j k}}}{\sum_{n=1}^{3} \exp \left(W_{j n}\right)}\right]
$$

\section{Results and Discussion}

\subsection{Estimation Results}

A nationwide CE survey of 1000 randomly chosen households was conducted by a professional polling firm through person-to-person interviews in May 2017. Each household provided four observations. Thus, we obtained a dataset size of 4000 (= 1000 respondents $\times 4$ choice sets). The respondents were made up of householders or housewives aged over 20 and under 65 years to reflect the characteristics of their household. Prior to conducting the main survey, 30 people were surveyed in advance to help raise respondents' understanding of the questionnaire. Table 2 summarizes the distribution of responses to the choice experiment questions. Of the total 4000 responses, the number of responses for the chosen alternatives A, B, and status quo alternative were 1335, 1631, and 1034, respectively.

Table 2. Distribution of the responses to the choice experiment questions.

\begin{tabular}{cccccccccc}
\hline & $\begin{array}{c}\text { Choice } \\
\text { Set 1 }\end{array}$ & $\begin{array}{c}\text { Choice } \\
\text { Set 2 }\end{array}$ & $\begin{array}{c}\text { Choice } \\
\text { Set 3 }\end{array}$ & $\begin{array}{c}\text { Choice } \\
\text { Set 4 }\end{array}$ & $\begin{array}{c}\text { Choice } \\
\text { Set 5 }\end{array}$ & $\begin{array}{c}\text { Choice } \\
\text { Set 6 }\end{array}$ & $\begin{array}{c}\text { Choice } \\
\text { Set 7 }\end{array}$ & $\begin{array}{c}\text { Choice } \\
\text { Set 8 }\end{array}$ & $\begin{array}{c}\text { Totals } \\
\text { First alternative }\end{array}$ \\
\hline Second alternative & 158 & 151 & 179 & 139 & 121 & 160 & 139 & 228 & 1335 \\
Status quo alternative & 124 & 106 & 151 & 105 & 124 & 160 & 134 & 130 & 1034 \\
Totals & 500 & 500 & 500 & 500 & 500 & 500 & 500 & 500 & 4000 \\
\hline
\end{tabular}

Table 3 reports the results of estimating the MNL model. All the coefficient estimates, except for day of week, are statistically distinguishable from zero at the $1 \%$ level. The reason why the coefficient estimate of the day of week attribute is not statistically significant is that people use residential NG regardless of whether it is a weekday or weekend. The expected signs for coefficient estimates for the five attributes are all negative, except for season of interruption.

Table 3. Estimation results of the multinomial logit model.

\begin{tabular}{|c|c|c|}
\hline Variables $^{\text {a }}$ & Multinomial Logit Coefficient Estimates ${ }^{c}$ & \\
\hline$A S C^{\mathrm{b}}$ & $-0.4118^{\#}$ & $(-3.67)$ \\
\hline Duration of interruption & $-0.0029^{\#}$ & $(-3.03)$ \\
\hline Season of interruption & $0.1523^{\#}$ & $(3.57)$ \\
\hline Time of day & $-0.0868^{\#}$ & $(-2.05)$ \\
\hline Day of week & -0.0573 & $(-1.24)$ \\
\hline Price & $-0.0295^{\#}$ & $(-7.96)$ \\
\hline Number of observations & 4000 & \\
\hline Wald-statistic ( $p$-value $)^{\mathrm{d}}$ & $265.96(0.000)$ & \\
\hline Log-likelihood & -4259.79 & \\
\hline
\end{tabular}

Notes: ${ }^{\mathrm{a}}$ The variables are defined in Table $1 ;{ }^{\mathrm{b}}$ ASC refers to alternative-specific constants that represent dummies for the respondents choosing the baseline status alternative; ${ }^{\mathrm{c} \#}$ Indicates statistical significance at the $1 \%$ level, and $t$-values are reported in parentheses beside the estimates; ${ }^{\mathrm{d}}$ The null hypothesis is that all the parameters are zero and the corresponding $p$-value is reported in parentheses beside the statistic.

The coefficient estimates for duration of interruption and time of day have negative signs. Thus, one unit decrease in the level of the duration of interruption attribute increases the public utility. Avoiding the baseline status of the time of day attribute also decreases the utility. This seems to be the public utility decrease when residential NG supply interruption occurs at off-daytime than daytime, since people usually stay at home after going to work or school. The coefficient for price also has 
a negative sign. This implies that, as the price goes up, the utility decreases. This result is quite reasonable, given that the price negatively contributes to the utility. On the other hand, the coefficient estimate for season of interruption has a positive sign. Avoiding the baseline status of the season of interruption attribute increases the utility.

\subsection{MWTP Estimates for Each Attribute}

Finally, the MWTP estimates for a decrease in the level of each attribute can be derived employing Equation (2). The results of estimating the MWTP values are provided in Table 4. The MWTP estimates for a one-minute decrease in duration of interruption, avoiding interruption during winter rather than non-winter, and preventing interruption during off-daytime rather than daytime, are obtained as $0.10 \%, 5.16 \%$, and $2.94 \%$, respectively, of the residential NG bill. These values are interpreted as the economic value of improving NG supply reliability in South Korea. Table 4 also presents the 95\% confidence intervals for the MWTP estimates, which are computed using the procedures given in Krinsky and Robb [22].

Table 4. Estimation results of marginal willingness to pay (MWTP) values.

\begin{tabular}{lccc}
\hline & \multicolumn{3}{c}{ MWTP Per Household Per Month } \\
\cline { 2 - 4 } & Estimates & t-Values & 95\% Confidence Intervals \\
\hline Avoidance of one minute's interruption & $0.1 \%^{* *}$ & 2.47 & $0.03-0.19 \%$ \\
\hline $\begin{array}{c}\text { Season of interruption (non-winter rather } \\
\text { than winter) }\end{array}$ & $5.16 \%^{*}$ & 3.06 & $2.10-8.89 \%$ \\
\hline $\begin{array}{c}\text { Time of day when the interruption occurs } \\
\text { (daytime rather than off-day time) }\end{array}$ & $2.94 \%{ }^{* *}$ & 1.98 & $0.09-6.10 \%$ \\
\hline $\begin{array}{c}\text { Day of week when the interruption occurs } \\
\text { (weekday rather than weekend) }\end{array}$ & $1.94 \%$ & 1.27 & $1.14-5.00 \%$ \\
\hline $\begin{array}{l}\text { Notes: }{ }^{*} \text { and ** indicate statistical significance at the 1\% and 5\% levels, respectively. The confidence intervals are } \\
\text { computed using the procedures given in Krinsky and Robb [18]. }\end{array}$
\end{tabular}

\subsection{Discussion of the Results}

Using the information presented in Table 4, we can estimate the household WTP for avoiding a situation in which the residential NG supply is interrupted. To illustrate this process, the authors arbitrarily compose three hypothetical situations using the information given in Table 1. For example, in Table 5, Situation A means that the residential NG supply is interrupted for one hour during winter, off-daytime, and weekday. The household WTP for avoiding Situation A is calculated to be a $6 \%$ increase in residential NG bill. A more detailed calculation process is as follows.

$0.1 \% / \min \times 60 \min +5.16 \% \times 0($ Winter $)+2.94 \% \times 0($ Off-daytime $)+1.94 \% \times 0($ Weekend $)=6.00 \%$

Table 5. Results of computing household willingness to pay (WTP) for avoiding the situations in which the residential natural gas (NG) supply is interrupted.

\begin{tabular}{cccc}
\hline & Situation A & Situation B & Situation C \\
\hline Duration of interruption & $60 \mathrm{~min}$ & $1 \mathrm{~h}$ & $20 \mathrm{~min}$ \\
\hline Season of interruption & Winter & Non-winter & Non-winter \\
\hline Time of day when the interruption occurs & Off-daytime & Off-daytime & Daytime \\
\hline $\begin{array}{c}\text { Day of week when the interruption occurs } \\
\text { situation expressed in percentage of an } \\
\text { increase in residential NG bill }\end{array}$ & Weekend & Weekend & $11.16 \%$ \\
\hline
\end{tabular}

The above analysis results have a variety of potential uses. First, by using these findings, one can identify which attributes people value. According to the estimated utility function, the absolute 
value of the coefficient estimate for season of interruption among the four attributes was the greatest. On the other hand, the absolute value of the coefficient estimate for duration of interruption was the smallest. Therefore, if the cost of improving the NG supply reliability is the same, it would be better to concentrate on avoiding interruption during winter rather than non-winter, than to reduce interruption by one minute during residential NG supply interruption. Second, using Tables 3 and 4, we can not only calculate the economic value of improving NG supply reliability for a variety of alternatives, but also make alternatives that result in a specific value of NG supply reliability. Alternatives may be proposed that satisfy the levels of acceptable value of NG supply reliability within the scope that the total costs do not exceed the total benefits.

\section{Conclusions}

This article aimed to examine the economic value of improving NG supply reliability in South Korea. To this end, the CE technique was adopted using the data from a nationwide survey of 1000 households. The four attributes of NG supply reliability considered in this study were (a) the duration of residential NG supply interruption; (b) the season when residential NG supply interruption takes place; (c) the time when residential NG supply interruption occurs; and (d) the day when residential NG supply interruption happens.

The coefficients for the utility function were statistically significant when estimated by applying the MNL model. The results showed that decreasing the duration of interruption, avoiding interruption during winter rather than non-winter, and preventing interruption during off-daytime rather than daytime increase the utility. More specifically, the economic values of improving NG supply reliability for reducing one minute of interruption during NG supply interruption, avoiding interruption during winter rather than non-winter, and preventing interruption during off-daytime rather than daytime are reflected as increases of $0.10 \%, 5.16 \%$, and $2.94 \%$, respectively, through an increase in the residential NG bill.

The value may vary depending on the times at which value judgment is made, because the economic technique used in this study is a stated preference approach, which analyses the data regarding the public preference. For example, when the economy is booming, the economic value of improving NG supply reliability can be measured as being higher, whereas, when the economy is in a recession, the value can be estimated to be lower. In addition, the economic value of improving NG supply reliability depends on the economic situation, social atmosphere, and NG supply situation, so it is difficult to maintain the specific value. Therefore, it is necessary to conduct a study at regular intervals on the value of NG supply reliability. It is possible to grasp the trajectory whose value changes with the lapse of time, and it is also possible to predict the future value with the result.

Additionally, this article seems to contribute to the literature in a research perspective. First, the article utilized a CE technique to look into the economic value of the attributes of improving NG supply reliability and found that the application was successful because the estimation results were statistically meaningful and the respondents actively participated in the CE survey. Improved power supply reliability is not just a problem for South Korea but an important issue for the worldwide, especially for developing countries [23-27]. Thus, comparison of the results from our work with those from future works that will be applied in other countries will yield new implications.

Author Contributions: All the authors participated in writing this paper. H.-J.K. wrote a large part of the paper and educated the interviewers; S.-M.K. collected and compiled the necessary background data for the study and prepared the CE questionnaire, which was essential for the data collection; and S.-H.Y. performed statistical analysis and supervised the entire process of writing the paper.

Acknowledgments: This work was supported by the Korea Institute of Energy Technology Evaluation and Planning (KETEP) and the Ministry of Trade, Industry \& Energy (MOTIE) of the Republic of Korea (No. 20184030202230).

Conflicts of Interest: The authors declare no conflict of interest. 


\section{References}

1. Korea Gas Safety Corporation. Statistics of Natural Gas in Korea. 2017. Available online: http://http: / /www.kgs.or.kr (accessed on 20 September 2018).

2. London Economics. Estimating Value of Lost Load; Final Report to OFGEM. 2011. Available online: https:/ / www.ofgem.gov.uk/ofgem-publications/40961/london-economics-estimating-value-lostload-final-report-ofgempdf (accessed on 19 April 2018).

3. Hartman, R.S.; Doane, M.J.; Woo, C.K. Consumer rationality and the baseline status. Q. J. Econ. 1991, 106, 141-162. [CrossRef]

4. Beenstock, M.; Goldin, E. Priority pricing in electricity supply: An application for Israel. Resour. Energy Econ. 1996, 19, 175-189. [CrossRef]

5. Carlsson, F.; Martinsson, P.; Akay, A. The effect of power outages and cheap talk on willingness to pay to reduce outages. Energy Econ. 2011, 33, 790-798. [CrossRef]

6. Jang, J.; Lee, J.; Yoo, S.H. The public's willingness to pay for securing a reliable natural gas supply in Korea. Energy Policy 2014, 69, 3-13. [CrossRef]

7. Min, S.H.; Lim, S.Y.; Yoo, S.H. Consumer's willingness to pay a premium for eco-labeled LED TVs in Korea: A contingent valuation study. Sustainability 2017, 9, 814.

8. Lim, S.Y.; Kim, H.Y.; Yoo, S.H. Public willingness to pay for transforming Jogyesa Buddhist temple in Seoul, Korea into a cultural tourism resource. Sustainability 2016, 8, 900. [CrossRef]

9. Wang, J.; Ge, J.; Ma, Y. Urban Chinese consumers' willingness to pay for pork with certified labels: A discrete choice experiment. Sustainability 2018, 10, 603. [CrossRef]

10. Vanstockem, J.; Vranken, L.; Bleys, B.; Somers, B.; Hermy, M. Do looks matter? A case study on extensive green roofs using discrete choice experiments. Sustainability 2018, 10, 309. [CrossRef]

11. Arrow, K.; Solow, R.; Portney, P.R.; Leamer, E.E.; Radner, R.; Schuman, H. Report of the NOAA panel on contingent valuation. Fed. Regist. 1993, 58, 4601-4614.

12. Hensher, D.A.; Greene, W.H. The mixed logit model: The state of practice. Transportation 2003, 30, $133-176$. [CrossRef]

13. Carlsson, F.; Martinsson, P. Does it matter when a power outage occurs? A choice experiment study on the willingness to pay to avoid power outages. Energy Econ. 2008, 30, 1232-1245. [CrossRef]

14. Abdullah, S.; Mariel, P. Choice experiment study on the willingness to pay to improve electricity services. Energy Policy 2010, 38, 4570-4581. [CrossRef]

15. Hensher, D.A.; Shore, N.; Train, K. Willingness to pay for residential electricity supply quality and reliability. Appl. Energy 2014, 115, 280-292. [CrossRef]

16. Ozbafli, A.; Jenkins, G.P. Estimating the willingness to pay for reliable electricity supply: A choice experiment study. Energy Econ. 2016, 56, 443-452. [CrossRef]

17. London Economics. The Value of Lost Load for Electricity in Great Britain; Final Report for OFGEM and DECC. 2013. Available online: https:/ / www.ofgem.gov.uk/ofgem-publications/82293/london-economicsvalue-lost-load-electricity-gbpdf (accessed on 19 April 2018).

18. Moeltner, K.; Layton, D.F. A censored random coefficients model for pooled survey data with application to the estimation of power outage costs. Rev. Econ. Stat. 2002, 84, 552-561. [CrossRef]

19. Hensher, D.A.; Rose, J.; Greene, W.H. The implications on willingness to pay of respondents ignoring specific attributes. Transportation 2005, 32, 203-222. [CrossRef]

20. Morrison, M.; Nalder, C. Willingness to pay for improved quality of electricity supply across business type and location. Energy J. 2009, 30, 117-133. [CrossRef]

21. McFadden, D. Conditional logit analysis of qualitative choice behaviour in frontiers in econometrics. In Frontiers in Econometrics; Zarembka, P., Ed.; Academic Press: New York, NY, USA, 1973; pp. 105-142.

22. Krinsky, I.; Robb, A.L. On approximating the statistical properties of elasticities. Rev. Econ. Stat. 1986, 68, 715-719. [CrossRef]

23. Lim, S.Y.; Lim, K.M.; Yoo, S.H. External benefits of waste-to-energy in Korea: A choice experiment study. Renew. Sustain. Energy Rev. 2014, 34, 588-595. [CrossRef]

24. Lim, S.Y.; Kim, H.J.; Yoo, S.H. Assessing the external benefits of contaminated soil remediation in Korea: A choice experiment study. Environ. Sci. Pollut. Res. 2018, 25, 17216-17222. [CrossRef] 
25. Sagebiel, J. Preference heterogeneity in energy discrete choice experiments: A review on methods for model selection. Renew. Sustain. Energy Rev. 2017, 69, 804-811. [CrossRef]

26. Reinders, A. Perceived and Reported Reliability of the Electricity Supply at Three Urban Locations in Indonesia. Energies 2018, 11, 140.

27. Jimenez, R.; Serebrisky, T.; Mercado, J. What does "better" mean? Perceptions of electricity and water services in Santo Domingo. Utilities Policy 2016, 41, 15-21. [CrossRef]

(C) 2019 by the authors. Licensee MDPI, Basel, Switzerland. This article is an open access article distributed under the terms and conditions of the Creative Commons Attribution (CC BY) license (http:/ / creativecommons.org/licenses/by/4.0/). 